\title{
Osteogenesis imperfecta in a 3,000-year-old mummy
}

\author{
Eve J. Lowenstein
}

Published online: 11 February 2009

(C) Springer-Verlag 2009

The past remains integral to us all, individually and collectively. We must concede the ancients their place...but their past is not simply back there, in a separate and foreign country, it is assimilated in ourselves and resurrected in an ever-changing present.

David Lowenthal [3]

The partially reconstructed skull is the remains of an Egyptian mummy, origins dated circa 1000 BC. Thought to be remains of a monkey, a first further investigation by paleopathologists revealed that these findings are more consistent with the remains of an infant affected by osteogenesis imperfecta (OI). The flattening of the vertical axis and widening of the transverse axis are consistent with a tam-o-shanter deformity (Fig. 1). Studies also revealed the remains to harbor deformed dentition consistent with dentinogenesis imperfecta and thin bones (Fig. 2).

Paleopathology, literally meaning "ancient suffering", is the study of disease through evaluation of ancient remains [1]. Paleomedical studies offer a unique perspective and inimitable insights into the history and evolution of disease and humanity. Napoleon Bonaparte is quoted with saying: "History is the version of past events that people have decided to agree upon." Paleomedical studies offer tools to impartially evaluate the facts of the past. Studies of preserved human remains have been conducted in a scientific manner for over 100 years, with numerous insights gained into public health management, disease epidemiology, and ancient medical practices. The paleopathologic study of human remains involves the technology and knowledge of a

\section{E. J. Lowenstein $(\square)$}

Division of Dermatology,

Brookdale Hospital Medical Center,

1 Brookdale Plaza, Brooklyn, NY 11212, USA

e-mail: evlow13@yahoo.com broad range of disparate specialties. A remarkable array of diseases are well substantiated in the paleorecord. Diseases evidenced in the paleorecord include trauma, congenital anomalies, circulatory disorders, diseases of the skeleton and joints, infectious, neoplastic, endocrine, nutritional, metabolic and hematologic disorders, to name a few. This being said, a healthy dose of skepticism is appropriate in considering reported findings. Many accounts of pseudopathology secondary to diagenesis (physical or chemical changes occurring after death) are recorded in the literature $[4,5]$. For instance, elevated soil pressure, poor drainage, and acidic soil conditions have resulted in long bone decalcification and warping falsely suggestive of rickets. Similarly, beetle and rodent gnawing at skulls has resulted in "rodent ulcers" suggestive of antemortem disease or trauma. In many cases, only where bone healing can be detected is it possible to ascribe damage to a disease process affecting the living. Thus, a critical and cautious open mind is important in reviewing these reports.

Osteogenesis imperfecta, also known as Vrolik's syndrome, is a rare but debilitating group of congenital diseases of the connective tissue. This heterogenous group of disorders (types I-VIII) is characterized by easy bone breakability. The majority of cases are caused by an autosomal dominant heritable error in type I collagen. Type I OI is the most common form. In this familial disorder, individuals tend to reach normal or slightly shorter stature, but bones tend to fracture easily; most fractures occur before puberty. They tend to have triangular face and skoliosis. Affected individuals have blue sclera, easy bruising, joint laxity, dental disorder, and hearing disorder.

Skull findings in OI include a membranous calvarium with multiple wormian bones (supernumerary ossicles of the cranial vault: formations associated with insufficient rate of suture closure and regarded as "epigenetic" and "hypostotic" traits), platybasia, basilar impression, and 


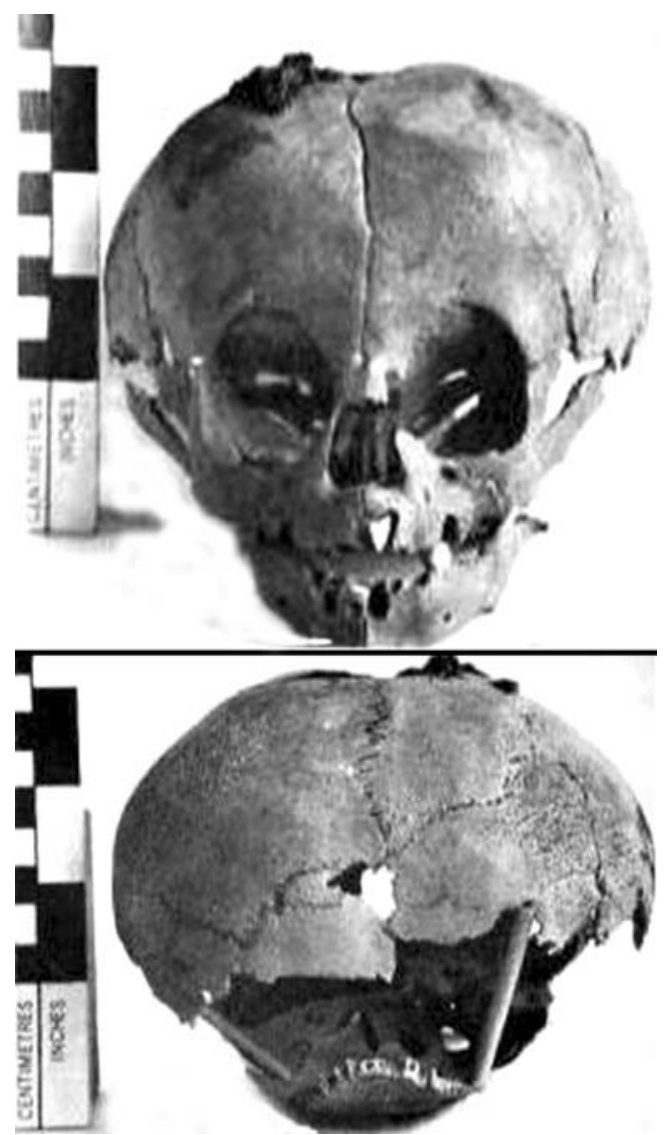

Fig. 1 Remains of an infant affected by osteogenesis imperfecta. The flattening of the vertical axis and widening of the transverse axis are consistent with a tam-o-shanter deformity (reprinted from [2] with permission)

basilar invagination as combined or isolated abnormalities. These three abnormalities and wormian bones were predominantly found in OI types III and IV as well as in patients exhibiting dentinal abnormality. Most forms of OI result from mutations in the genes that encode either the proalpha1 or proalpha 2 polypeptide chains that comprise type I collagen molecules, the major structural protein of

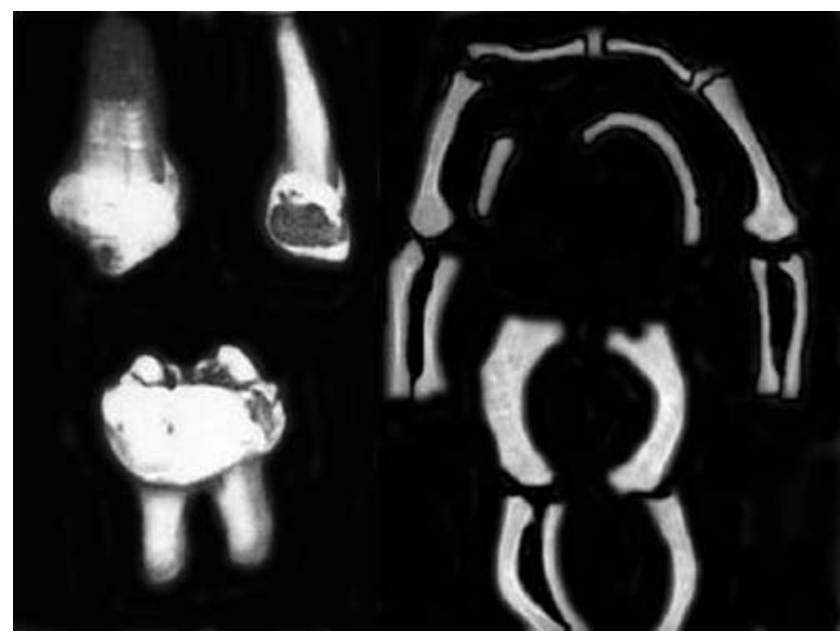

Fig. 2 Same child as in Fig. 1. Remains to harbor deformed dentition consistent with dentinogenesis imperfecta (left) and thin bones (right; reprinted from [2] with permission)

bone. Genetic testing is available which may confirm the diagnosis, but negative testing cannot rule out the diagnosis, which may rest on a rare recessive or unknown gene mutation.

\section{References}

1. Aufderheide AC, Rodriguez-Martin C (1998) The Cambridge encyclopedia of human paleopathology. Cambridge University Press, Cambridge

2. Gray P (1969) A case of osteogenesis imperfect, associated dentinogenesis imperfect, dating from antiquity. Clin Radiol 20:106-108

3. Lowenthal D (1985) The past is a foreign country. Cambridge University Press, Cambridge

4. Rothschild B, Martin L (1993) Diagenesis. Paleopathology: disease in the fossil record. CRC, Boca Raton, FL, pp 43-78

5. Wells C (1967) Pseudopathology. Chapter 1. In: Brothwell D, Sandison A (eds) Diseases in antiquity. Thomas, Springfield, IL, pp 5-19 